Research Article

\title{
Functional outcome in distal third tibial fractures treated with interlocking nailing
}

\author{
K. Thanigaimani*
}

Department of Orthopedics, Government Chengalpattu Medical College, Chengalpattu, Tamilnadu, India

Received: 08 July 2016

Accepted: 13 July 2016

\section{*Correspondence:}

Dr. K.Thanigaimani,

E-mail: orthomani2002@gmail.com

Copyright: (c) the author(s), publisher and licensee Medip Academy. This is an open-access article distributed under the terms of the Creative Commons Attribution Non-Commercial License, which permits unrestricted non-commercial use, distribution, and reproduction in any medium, provided the original work is properly cited.

\section{ABSTRACT}

Background: The purpose of this study was to evaluate the functional outcome in distal third tibial fractures not extending into the ankle joint treated with interlocking nailing.

Methods: Twenty eight patients of distal tibial fractures were admitted in our orthopaedic department .5 patients were lost to follow up. Hence 23 patients were studied. After initial resuscitation and immobilization, they were taken up for internal fixation. Depending upon their general condition and associated injuries the time interval for surgery varied from one day to two weeks. They were periodically followed at 6 weeks, $3^{\text {rd }}$ month, $4^{\text {th }}$ month, $6^{\text {th }}$ month and every eight weeks thereafter, till fracture union.

Results: No patient in the study went in for non-union. All the fractures united well. However two patients had osteomyelitis which was settled after nail removal and appropriate antibiotics. One had ankle stiffness. The outcome was analysed with Johner and Wruh criteria.

Conclusions: The outcome of treatment of distal tibial fractures is mostly affected by the severity of the injury and associated complications or injury. The study showed that interlocking nailing gives good results in distal third tibial fractures.

Keywords: Distal tibial fractures, Interlocking nailing, Ankle stiffness

\section{INTRODUCTION}

The tibial diaphyseal fractures are relatively common fractures. They also prone for complications especially the extra articular distal tibial fractures. The distal tibia is devoid of any muscle attachment and has sparse soft tissue coverage. It also has a wide medullary canal predisposing to the coronal plane malalignment. The proximity of ankle joint causes the rotational malalignment while fixing the fractures. Though there are various modalities of treatment for distal third fractures, choosing an ideal implant depends on the various factors, including patient characteristics. The dramatic success of interlocking nailing of femoral fractures led the surgeons to believe that similar results might be achieved when applied to the tibia. Because of its success, the indications have been extended to those of the proximal and distal metaphyseal region. ${ }^{1}$ The osteosynthesis of tibial fractures with a locked intramedullary nail is recommended by various authors due to the high union rates, low infection and deformity rates and good functional results. ${ }^{2}$ Although different treatment method developed for distal tibia fractures exist, the optimal method of fixation is still in debate. Most series of fractures of the tibia contain a proportion of fractures in the distal metaphysis which are wholly extra articular. There is evidence that the mechanism of injury and the prognosis of these fractures are different from those of pilon fractures, but their proximity to the ankle makes the primary treatment more complicated than that for 
fractures of tibial diaphysis. This justifies a separate review of the prognosis of these injuries. Hence this study was conducted to analyse the outcome in these fractures treated with interlocking nails.

\section{METHODS}

This study was conducted in between January 2012 and January 2014. It is a prospective non randomized study. There were totally 28 cases for the study group formed. 5 patients were lost to follow up. Hence the total no patients were 23. There were 16 males and 7 females. The common mode of injury is road traffic accidents. The patients with symptoms suggestive of distal third tibia are examined both clinically and radiologically after intial resuscitation. Radiographs of the affected leg with knee and ankle joints were taken. The distance of the fracture from the joint line ranged from 5 to $11 \mathrm{~cm}$. All fractures were classified according to OTA system. There were totally eleven patients in type A, ten patients in type B, two patients in type $\mathrm{C}$. Pre-operative tibial nail size was determined. The nail length should permit end to be countersunk with the distal end centered in the distal epiphysis. Regional anaesthsia was used in all patients except two. Longitudinal midline patellar tendon splitting incision was used. Carm image intensifier was used. Reamed interlocking nailing done in all closed fractures Unreamed nailing done in compound fractures. Both proximal and distal locking was done in all cases. They were followed at six weeks, $3^{\text {rd }}$ month, $4^{\text {th }}$ month, $6^{\text {th }}$ month and every eight weeks thereafter. Fracture union is considered delayed when healing has not advanced after three months. Fracture is considered united when there is no tenderness and X-ray evidence of 3 out of 4 cortices union. Non-union was considered when there is no sign of healing after 6 months. Fracture union was defined as healing of at least 3 of 4 cortices on biplanar plain radiograph. Delayed union was defined as a lack of any healing on plain radiograph within 3 months. Nonunion was defined as a lack of any healing on plain radiograph within 6 months. Malunion was defined as more than $5^{\circ}$ of angular deformity or shortening of more than $1 \mathrm{~cm} .^{10,11}$

\section{Inclusion criteria}

- All skeletally mature patients with distal third tibial fracture

\section{Exclusion creteria}

- Fractures with intra-articular extension.

- Distal tibial fractures treated with other modalities.

- Segmental fractures

Depending upon the progress of fracture union partial and full weight bearing started. Knee joint Ankle joint and sub talar joint function assessed during periodic review. Any evidence of rotational deformity was observed periodically. The Johner and Wruh criteria was used to analyse the end results. This criteria includes non-union osteitis, amputations, neurovascular disturbances, deformity-varus/ valgus, anteversion/recurvatum, rotation, shortening, mobility, knee, ankle, subtalar joint, pain gait, sternuous activities.

\section{RESULTS}

The time of surgery varied from one day to two weeks. Total duration of hospital stay was 2 weeks to 8 weeks. 7 patients had associated injuries. One patient had chest injury which required prolonged stay in the hospital. The average time of radiological union was 16 weeks. No patient in our study went in for nonunion or amputation. However 2 patients had osteomyleitis which was settled after nail removal and antibiotics. No patient had developed neurovascular complications.

Table 1: The final outcome.

\begin{tabular}{|lll|}
\hline Result & $\begin{array}{l}\text { Total.no.of } \\
\text { patients }\end{array}$ & percentage \\
\hline excellent & 12 & 52.17 \\
\hline good & 8 & 34.78 \\
\hline fair & 1 & 4.35 \\
\hline poor & 2 & 8.69 \\
\hline
\end{tabular}

Table 2: Time of fracture union.

\begin{tabular}{|c|c|c|c|c|c|c|c|c|c|c|}
\hline \multirow{2}{*}{$\begin{array}{l}\text { Time of } \\
\text { radiological } \\
\text { union in weeks. }\end{array}$} & \multicolumn{2}{|c|}{ Excellent } & \multicolumn{2}{|c|}{ Good } & \multicolumn{2}{|c|}{ Fair } & \multicolumn{2}{|c|}{ Poor } & \multicolumn{2}{|c|}{ Total } \\
\hline & no & percentage & no & percentage & no & percentage & no & percentage & no & percentage \\
\hline$<=14$ & 7 & 58.34 & 2 & 25 & - & - & - & - & 9 & 39.4 \\
\hline $15-26$ & 5 & 46.2 & 5 & 62.5 & 1 & 100 & - & - & 11 & 47.8 \\
\hline$>26-39$ & - & - & 1 & 12.5 & - & & 1 & 50 & 2 & 8.7 \\
\hline$>39$ & - & - & - & - & - & - & 1 & 50 & 1 & 4.4 \\
\hline total & 12 & 100 & 8 & 100 & 1 & 100 & 2 & 100 & 23 & 100 \\
\hline
\end{tabular}


Table3: Nature of complications.

\begin{tabular}{|lll|}
\hline Complications & No.of patients & Percentage \\
\hline Osteomyelitis & 2 & 8.7 \\
\hline Varus/valgus union & 5 & 21.7 \\
\hline Recurvatum deformity & 0 & 0 \\
\hline Shortening & 5 & 21.7 \\
\hline Nonunion & 0 & 0 \\
\hline
\end{tabular}

5 patients had varus/valgus deformity ranging 2 to 5 degrees. Four patients had varus/valgus deformity ranging 6 to 10 degrees. No anteversion or recurvation deformity noted. Shortening measuring $0.5 \mathrm{~cm}$ found in 3 patients and $1 \mathrm{~cm}$ shortening was noted in 2 patients. All patients had full range of knee mobility. Two patients had ankle stiffness. 3 patients had $<75 \%$ ankle movement. All the patients had normal subtalar movements. 10 patients had anterior knee pain. Gait is normal in almost all patients except 3 patients. The mean time of union in many literature is around 4 months which is same in the present study. The variations in the results of functional outcome in various authors reflect the difficulties in distal third tibial fracture treatment. In this study, it was observed $85 \%$ (20) excellent (or) good results. $4.35 \%$ (1) showed fair results, $8.69 \%$ (2) of poor results. The much dreaded complications like nonunion, nail protrusion into the ankle have not been observed in the study. The poor outcomes were associated with comorbid conditions.

\section{DISCUSSION}

In between January 2012 and 2014, 28 distal tibial fractures were treated with interlocking nailing, 5 cases were lost to follow up. Hence total number of 23 cases was studied. There were 16 males and 7 females. In the series, the average age of the patients was $37.5 \pm 14.66$ years (range 18-65 years). George CB et al have also reported similar mean age (range $17-85$ years). ${ }^{5}$ Haydar AJ et al and Vallier et al both reported the mean age of 38 years in their series. ${ }^{7,6}$ Most of these fractures were sustained in road traffic accidents. In two patients fractures occurred due to the fall of heavy weight and there was one fracture following assault. The range of follow up from 4 months to 1 year 6 months. There were 18 closed fractures 5 compound fractures among which 4 patients were in grade I and one patient was in grade II as per gustillo- anderson classification. Left leg was affected in 10 patients and right leg in 13 patients. All the fractures were classified according to orthopaedic trauma association classification system. The time of presentation varied from immediately after the injury to one week after injury. Depending on the general condition of the patient the time taken for surgery varied from immediately to two weeks. Reamed interlocking nailing was done in all closed fractures and unreamed nailing in compound fractures. There is an associated fibular fracture in 19 patients, out of which 10 patients had upper and segmental fibular fracture, 5 patients had undisplaced middle third fibular fracture, 4 patients had lower third fibular fracture with syndesmotic disruption. On reviewing literature, in a study of Varsalona R, Liu GT evaluating the role of fibular fixation in distal tibial metaphyseal fractures they concluded "adjunctive fixation of concomitant fibular fractures without associated syndesmotic or ankle pathology is not necessary in surgically stabilized extra-articular metaphyseal fractures of the distal tibia". ${ }^{\circ}$ Although fibular fixation has been shown to improve stability of distal tibial fractures, there has been increased potential for soft tissue-related complications and a delay of tibial fracture healing. Whereas Egol, Kenneth A et al concludes that the proportion of fractures that lost alignment was smaller among those receiving stabilization of the fibula in conjunction with interlocking nailing compared with those receiving interlocking nailing alone. ${ }^{12}$ In present study fibular plating was done in 4 patients to achieve reduction. Patients were encouraged to get out of bed on second day. Knee and ankle mobilization started immediately. Most of the patients were allowed partial weight bearing after 6 weeks based on clinical and radiological evaluation. Dynamization was performed in five patients at a mean time of 10 weeks. Average time for clinical and radiological union was 4 months (3 months to 8 months). Kruppa et al reported $19 \%$ non-union and $23.8 \%$ malunion in their series. ${ }^{4}$

In the study, series $85 \%$ patients obtained good to excellent results (excellent $52.17 \%$, good $34.78 \%$ ) which are comparable to the $86.3 \%$ satisfactory or excellent results of the series of Tyllinakis et al. who treated 73 patients with non-pilon distal tibia fractures using Interlocking Intramedullary nailing. ${ }^{9}$

\section{CONCLUSION}

The study shows that interlocking nailing gives good results in distal third tibial fractures. Acceptable alignment and range of motion can be achieved. Fibular fixation needs to be done only in patients with syndesmotic disruption. Other patients can be treated with interlocking nailing alone. Some cases because of associated injuries and comorbid condition ended with complications like ankle stiffness and infection. But still, we were able to achieve union in all the cases. However these cases go down by one level in functional assessment score.

\section{Funding: No funding sources \\ Conflict of interest: None declared \\ Ethical approval: The study was approved by the institutional ethics committee}

\section{REFERENCES}

1. Robinson CM, Mclauchlan GJ, Mclean IP. Distal metaphyseal fractures of the tibia with minimal involvement of the ankle: classification and 
treatment by locked intramedullary nailing. J Bone Joint Surg Br. 1995;77:781-7.

2. Karladani AH, Granhed H, Edshage B, Jerre R, Styf J. Displaced tibial shaft fractures: a prospective randomized study of closed intramedullary nailing versus cast treatment in 53 patients. Acta Orthop Scand. 2000;71(2):160-7.

3. Johner R, Wruhs. Classification of tibial shaft fractures and correlation with results after rigid internal fixation. Clin Orthop. 1983;178:7-25.

4. Kruppa, Christiane G, Hoffmann, Martin F, Sietsema, Debra L et al. Outcomes in the treatment of distal tibial fractures treated with intramedullary nails. J Orthop Trauma. 2015;3:247-54

5. Babis GC, Benetos IS, Zoubos AB, Soucacos PN. The effectiveness of the external distal aiming device in intramedullary fixation of tibial shaft fractures. Arch Orthop Trauma Surg. 2007;127:9058.

6. Vallier HA, Cureton BA, Patterson BM. Randomized, prospective comparison of plate versus intramedullary nail fixation for distal tibia shaft fractures. J Orthop Trauma. 2011;0:1-514.
7. Haydar AJ, Hussain AL, Deeb A, Choudhary AK. Anterior knee pain following intramedullary nailing of tibial shaft fractures: does bony portal point in the sagittal plane affect the outcome?. Eur J Orthop Surg Traumatol. 2005; 15:113-7.

8. Varsalona R, Liu GT. Distal tibial metaphyseal fractures: the role of fibular fixation. Strat Traum Limb Recon. 2006;1:42-50.

9. Tyllianakis M, Megas P, Giannikas D, Lambiris E. Interlocking intramedullary nailing in distal tibial fractures. Orthopedics. 2000;23(8):805-8.

10. Pugh KJ, Wolinsky PR, Mcandrew MP, Johnson KD. Tibial pilon fractures: a comparison of treatment methods. J Trauma. 1999;47:937-41.

11. Mcferray MA, Smith SW, Boulas HT, Schwartz HS. Complications encountered in the treatment of pilon fractures. J Orthop Trauma. 1992;6:195-200.

12. Egol, Kenneth A, Weisz, Russell, Hiebert, Rudi et al. Does Fibular Platting improve alignment after intramedullary nailing of distal metaphyseal tibia fractures. J Orthop Trauma. 2006;20(2):94-103.

Cite this article as: Thanigaimani $\mathrm{K}$. Functional outcome in distal third tibial fractures treated with interlocking nailing. Int J Res Orthop 2016;2:91-4. 